\title{
Brazilian version of headache management self-efficacy scale
}

\author{
Rebeca Veras de Andrade Vieira ${ }^{1,2}$ (i), Fernando Kowacs ${ }^{3,4}$ (i), Renata Gomes Londero 3 , (iD), \\ Liselotte Menke Barea ${ }^{4,6}$ (D), Vanise Grassi ${ }^{6}$ (D) , Isadora Silveira Ligório² (iD), Francielle Machado Beria2 (iD, \\ William Barbosa Gomes² (i), Gustavo Gauer² (iD
}

\footnotetext{
${ }^{1}$ Universidade do Vale do Rio dos Sinos, São Leopoldo, Rio Grande do Sul, Brazil.

2Universidade Federal do Rio Grande do Sul, Porto Alegre, Rio Grande do Sul, Brazil.

${ }^{3}$ Hospital Moinhos de Vento, Porto Alegre, Rio Grande do Sul, Brazil.

${ }^{4}$ Universidade Federal de Ciências da Saúde de Porto Alegre, Porto Alegre, Rio Grande do Sul, Brazil.

${ }_{5}^{5}$ Serviço de Neurologia, Hospital de Clínicas de Porto Alegre, Porto Alegre, Rio Grande do Sul, Brazil.

${ }^{6}$ Santa Casa de Misericórdia de Porto Alegre, Porto Alegre, Rio Grande do Sul, Brazil.
}

\section{$凶$}

Rebeca Veras de Andrade Vieira +55 (51) $98118-6440$

rebecavieirapsico@gmail.com

Edited by:

Marcelo Moraes Valença

Keywords:

migraine

self-efficacy

disability

psychometrics

catastrophization

migraine disorders

\begin{abstract}
Background

Headache-management self-efficacy has been associated with pain severity and headache-related disability.

Objective

The aim of this study was to test the cross-cultural adaptation and psychometric properties of a Brazilian version of the Headache Management Self-Efficacy Scale (HMSE) in a sample of patients coming from three tertiary headache centers in Brazil.

Methods

137 migraine outpatients completed the Headache Management Self-Efficacy Scale (HMSE) and measures of psychopathological symptoms, pain catastrophizing, depression, anxiety, quality of life and headache-related disability.

Results

HMSE-10 showed good reliability $(a=0.84)$ and adequate corrected item-total correlation, ranging from 0.46 to 0.64 . HMSE- 10 was positively correlated with 6 of 8 domains of overall health status and negatively correlated with psychopathological symptoms, depression, anxiety, pain catastrophizing, headache-related disability, headache frequency and headache intensity. The difference between the means of the episodic and chronic headache patients had a magnitude of moderate effect in all the study measures, being headache-related disability the largest one found $(d=0.68)$. Along with headache intensity and depression, self-efficacy beliefs were predictors of headache-related disability.

\section{Conclusions}

The Brazilian short version of Headache Management Self-Efficacy Scale (HMSE-10) was revealed as a valid and reliable measure of headache-specific Efficacy Scale beliefs.
\end{abstract}




\section{Introduction}

In the context of headache management, self-efficacy (SE) beliefs refer to patient's confidence that they can take actions to prevent headache episodes or manage headache-related pain and disability. 'In young people, headache management self-efficacy is considered an important resilience factor, with an impact on functional capacity and school functioning. ${ }^{2}$ Moreover, it has been shown that SE beliefs mediate the association between pain severity and disability ${ }^{3}$, moderates the relationship between headache frequency and frequency of stressful events ${ }^{4}$, being considered a psychological factor relevant to all headache patients. ${ }^{5}$ In the case of chronic migraine patients with medication overuse, SE beliefs are considered one of the psychological dimensions that should be targeted in order to reduce negative effects on functioning and quality of life. ${ }^{6}$

Even though being highly self-efficacious represents a key factor in successful headache management, it is still observed in Brazil an absence of instruments to evaluate SE beliefs in these patients. The aim of the present study was to test the cross-cultural adaptation and psychometric properties of a Brazilian version of the Headache Management Self-Efficacy Scale (HMSE) in a sample of patients from three tertiary headache centers in Brazil.

\section{Methods}

\section{Participants}

The sample was composed by 137 patients with a migraine diagnosis made by experienced neurologists according to International Classification of Headache Disorders $3^{\text {rd }}$ Edition - Beta version (2013). ${ }^{7}$ Exclusion criteria were having a psychotic disorder, a cognitive impairment, or the patient lacking time. The age of participants ranged from 18 to 65 years old $(M=43.70 ; S D=12.74)$. Patients were selected among the outpatients registered at the Headache Unit of the Hospital de Clínicas de Porto Alegre (HCPA) and o Irmandade Santa Casa de Misericórdia de Porto Alegre (ISCMPA), both reference public hospitals, as well as at the Headache Unit of the Hospital Moinhos de Vento (HMV), a reference private hospital in South Brazil. All three headache centers are in city of Porto Alegre, state capital of Rio Grande do Sul, Brazil.

\section{Instruments}

Interview

A semi structured interview was held to characterize the sample and to evaluate clinical headache parameters, such as duration of disorder in years (DD), time patient has been in treatment (DT), headache frequency in the last three months (HF), headache intensity attributed by the participants to their pain in the last three months in a scale ranging from $0-10(\mathrm{HI})$, and screening for medication overuse headache diagnosis.

\section{Headache Management Self-Efficacy Scale (HMSE)}

The instrument was developed by French et al. ${ }^{1}$ and aims to assess individual's perception of their ability to take actions to prevent and to manage headaches and headache-related disability. The scale consists of 25 items, which were generated by individuals experienced in the treatment of chronic headache problems and include items both inquiring about individual's confidence in their ability to prevent and to manage their headaches episodes. The items are rated on a 7-point scale ranging from $1=$ strongly disagree to $7=$ strongly agree. The instrument shows excellent reliability, with Cronbach's at 0.90 for the 25 item total scale.

\section{Self-Reporting Questionnaire (SRQ)}

It is a questionnaire for the screening of psychiatric disorders at the primary care level ${ }^{10}$ composed by 24 questions subdivided in two sections: 20 questions aim at "neurotic" disorders detection and the remaining four questions track "psychotic" disorders. The "neurotic" disorders correspond to mood, anxiety and somatoform disorders, assessed by the SCID-IV -TR (Structured Clinical Interview for DSM-IV$T R)^{11}$. In the present study we used only the first section (neurotic disorders). The individual fulfills criteria for a possible neurotic disturbance by scoring 7 or more points in this subscale.

\section{Short Form Health Questionnaire (SF-36)}

The instrument is an indicator of overall health status and has eight scaled scores: vitality (VT), physical functioning $(P F)$, bodily pain (BP), general health perceptions $(G H)$, physical role functioning (PR), emotional role functioning $(E R)$, social role functioning (SF), and mental health $(\mathrm{MH}) .^{12}$

\section{Headache Impact Test (HIT-6)}

This is a 6-item questionnaire used to measure the impact of headaches on usual daily activities, including work, school, social activities, pain intensity, fatigue and bedtime, 
frustration, and concentration difficulties. ${ }^{13}$ Each item is answered on a 5 -point likert scale $(6=$ never, $8=$ rarely, $10=$ sometimes, $11=$ very often, $13=$ always $)$. The higher the score obtained, the greater the degree of impact. The instrument has good internal consistency, with Cronbach's alpha of 0.79 .

\section{Pain Catastrophizing Scale (PCS)}

The instrument was to assess catastrophizing as a style of negative cognitions related to pain ("catastrophizing" refers to a unique construct, evaluated from three dimensions: magnification, rumination and helplessness. The instrument shows a good level of internal consistency, with Cronbach's alphas varying from 0.86 to 0.93 among magnification, rumination and helpless subscales. ${ }^{14}$

\section{Patient Health Questionnaire 9 (PHQ-9) and Generalized Anxiety Disorder 7 (GAD-7)}

PHQ-9 and GAD-7 are instruments for the evaluation of depression and anxiety according to the criteria of the Diagnostic and Statistical Manual of Mental Disorders (DSM-IV), respectively. ${ }^{15}$ PHQ-9 is composed of nine items, distributed on a 4-point Likert scale: "0" (not at all) to "3" (nearly every day). The total score varies from 0 to 27 , being considered a positive indicator of major depression the value greater or equal to 10 is an instrument composed of seven items, distributed on a 4-point Likert scale: "0" (not at all) to "3" (nearly every day). The sum of the scores ranges from 0 to 21 . Values greater than or equal to 10 are positive indicators for anxiety disorders. In the headache field, both PHQ-9 and GAD-7 have been considered reliable and valid screening instruments for major depressive disorders and generalized anxiety disorders in patients with migraine. ${ }^{16,17}$

\section{Statistical Analysis}

Descriptive statistics were performed for the sociodemographic and clinical data of participants. Psychometric properties of HMSE were analyzed using factorial exploratory analysis principal axis method, with Oblimin rotation and considering eigenvalues above of 1 , internal stability and convergent validity. Internal stability was analyzed using Cronbach's a coefficient and convergent validity was investigated by correlating (HMSE) scores with the Self-Reporting Questionnaire (SRQ), PHQ-9, GAD-7, Pain Catastrophizing Scale (PCS), HIT-6 (Headache Impact Test), and SF-36. To evaluate possible associations between SE beliefs and sociodemographic measures, we run Pearson correlations for continuous variables (age) and t-test or ANOVA for categorical variables (income, educational level, marital status and laboral status). To compare possible mean differences in study measures in chronic, episodic migraine and group comparisons, t-tests were conducted, and effect size was calculated using the Cohen's D index. A linear multiple regression analysis (Enter method) was conducted to examine the relative contribution of headache intensity, headache frequency, psychopathological symptoms (SRQ), depression (PHQ9), anxiety (GAD-7), and SE beliefs to the prediction of headache-related disability. Inferential statistics were run using SPSS (Statistical Package for Social Sciences) version 22 , adopting a $5 \%$ significance level.

\section{Results}

A total of 137 patients from the three headache centers were included. Because some patients could not full fill all the instruments, the number of patients included in the calculation varied from 106 to 137 in each measure. Table 1 shows sociodemographic and clinical data of the sample.

Table 1. Sociodemographic and Clinical Data of the Sample $(n=137)$

\begin{tabular}{|c|c|}
\hline Sex & Female $(n=122,89.1 \%)$; Male $(n=15,10.1 \%)$ \\
\hline Age & 44.05 (12.8) \\
\hline $\begin{array}{l}\text { Education } \\
f(\%)\end{array}$ & $\begin{array}{l}\text { Elementary }=52(35.3 \%) ; \text { High School=51 }(34.7 \%) ; \\
\text { Professional }=11(7.5 \%) ; \text { College=19 (12.9\%); Post- } \\
\text { graduate }=14(9.6 \%)\end{array}$ \\
\hline $\begin{array}{l}\text { Income (in current minimum } \\
\text { wages) } \\
\text { Laboral Status }\end{array}$ & $\begin{array}{l}\text { Until= } 15(10.2 \%) \text {; From } 1 \text { to } 3=69(46.9 \%) \text {; From } \\
3 \text { to } 5=43(29.3 \%) \text {; From } 5 \text { to } 10=13(8.8 \%) \text {; More } \\
\text { than } 10=7(4.8 \%) \\
\text { Employed= } 69(46.9 \%) \text {; Unemployed= } 78(53.1 \%)\end{array}$ \\
\hline Marital status & $\begin{array}{l}\text { Single = } 37(25.2 \%) \text {; Married = } 60(40.8 \%) \text {; Live with } \\
\text { partner }=28(19 \%) ; \text { Divorced = } 17(11.6 \%) \text {; Widowed } \\
=5(3.4 \%)\end{array}$ \\
\hline $\begin{array}{l}\text { Diagnosis } \\
\text { DD (years) }\end{array}$ & $\begin{array}{l}\text { Episodic Migraine = } 109(75.2 \%) \text {; Chronic Migraine } \\
=21(14.5 \%) ; \\
\text { Medication Overuse Headache }=15(10.3 \%) \\
22.67(14.89)\end{array}$ \\
\hline DT (years) & $9.91(10.44)$ \\
\hline $\mathrm{HF} / \mathrm{HI}$ & $28.97(24.98) / 8.23(1.95)$ \\
\hline
\end{tabular}

Mean (standard deviation); DD = Duration of disease (in years), DT = duration of treatment (in years), HF = headache frequency in the last three months (in days), $\mathrm{HI}=$ headache intensity attributed by the participants to their pain in the last three months in a scale ranging from 0-10

In order to explore the underlining theoretical structure of the HMSE in the Brazilian sample, an exploratory factor analysis was applied. The Kaiser-Meyer-Olkin (KMO) measure of sampling adequacy was satisfactory $(\mathrm{KMO}=0.84)$ and Bartlett's test of sphericity was significant. A one-factor solution was supported and accounted for 
$25 \%$ of variance in the items. Factor loadings ranged from 0.13 to 0.72 . When factor analysis was re-runned excluding items with factor loading above 0.30 , the items left accounted only for $30 \%$ variance.

As in the study carried out by Cano-García and coworkers ${ }^{18}$, we chose to select only the items with the highest factorial loading (above 0.50). The items selected and their respective factor loadings are presented on Table 2 .

Table 2. HMSE-10 items and their respective factor loadings

\begin{tabular}{|c|c|}
\hline $\begin{array}{l}\text { Item Number- Brazilian Version of the item } \\
\text { Original version of the item (italic) }\end{array}$ & Factor loading \\
\hline $\begin{array}{l}\text { 4. Há coisas que eu posso fazer para reduzir a dor de cabeça. } \\
\text { There are things I can do to reduce headache pain. }\end{array}$ & 0.65 \\
\hline $\begin{array}{l}\text { 6- Uma vez que a dor de cabeça começa, não há nada que eu } \\
\text { possa fazer para controlá-la**. } \\
\text { Once I have a headache there is nothing I can do to control it. * }\end{array}$ & 0.57 \\
\hline $\begin{array}{l}\text { 11. Nada que eu faço impede que uma dor de cabeça leve se } \\
\text { torne forte*. } \\
\text { Nothing I do will keep a mild headache from turning into a bad } \\
\text { headache*. }\end{array}$ & 0.56 \\
\hline $\begin{array}{l}\text { 13- Eu consigo fazer coisas para controlar o quanto as dores de } \\
\text { cabeça interferem na minha vida } \\
\text { I can do thing to control how much my headaches interfere with } \\
\text { my life. }\end{array}$ & 0.74 \\
\hline $\begin{array}{l}\text { 15. Eu consigo fazer coisas para controlar o quanto dura uma } \\
\text { dor de cabeça. } \\
\text { I can do things that will control how long a headache lasts. }\end{array}$ & 0.61 \\
\hline $\begin{array}{l}\text { 17. Quando não estou sob muito estresse, eu consigo prevenir } \\
\text { muitas dores de cabeça. } \\
\text { When I'm not under a lot of stress, I can prevent many headaches. }\end{array}$ & 0.57 \\
\hline $\begin{array}{l}\text { 19. Eu consigo evitar que uma dor de cabeça leve atrapalhe o } \\
\text { meu dia, } \\
\text { se eu mudar a maneira como lido com a dor } \\
\text { I can keep a mild headache from disrupting my day by changing } \\
\text { the way I respond to the pain. }\end{array}$ & 0.67 \\
\hline $\begin{array}{l}\text { 22- Há coisas que eu posso fazer para prevenir dores de cabeça. } \\
\text { There are things I can do to prevent headaches. }\end{array}$ & 0.71 \\
\hline $\begin{array}{l}\text { 24- Eu consigo controlar a intensidade de uma dor de cabeça. } \\
\text { I can control the intensity of headache pain }\end{array}$ & 0.64 \\
\hline $\begin{array}{l}\text { 25- Eu consigo fazer coisas para enfrentar as minhas dores de } \\
\text { cabeça. } \\
\text { I can do things to cope with my headaches. }\end{array}$ & 0.75 \\
\hline
\end{tabular}

Extraction Method: Principal Component Analysis.

In this new version, $\mathrm{KMO}$ was also satisfactory $(\mathrm{KMO}=0.87)$ and Bartlett's test of sphericity was significant. Thus, a shortened version with 10 items of HMSE was obtained for the Brazilian sample. Finally, HMSE-10 proved to be satisfactory, with items accounting for $42 \%$ of total variance. Cronbach's a coefficient demonstrated good internal consistency for HMSE-10 ( $a=0.84$ ) and adequate corrected item-total correlation, ranging from 0.46 to 0.64 . Descriptive Statistics for Study Measures are presented in Table 3.
Table 3. Descriptive Statistics of Study Measures ( $n=137)$

\begin{tabular}{|l|c|c|c|}
\hline Measure & \multicolumn{1}{|l|}{ Mean (SD) } & \multicolumn{1}{|l|}{ Range } & Number of patients \\
\hline HMSE- 10 & $43.84(13.34)$ & 60 & 135 \\
\hline PHQ-9 & $10.27(6.65)$ & 27 & 136 \\
\hline GAD-7 & $10.22(6.16)$ & 21 & 137 \\
\hline PCS & $42.76(12.04)$ & 46 & 135 \\
\hline SRQ & $10.09(4.94)$ & 20 & 137 \\
\hline HIT-6 & $62.03(7.9)$ & 38 & 137 \\
\hline SF-36 & & & \\
\hline PF & $62.91(29.32)$ & 100 & 134 \\
\hline RP & $39.93(42.71)$ & 100 & 134 \\
\hline BP & $39.40(22.27)$ & 90 & 134 \\
\hline GH & $6.81(1.68)$ & 8 & 134 \\
\hline VT & $12.38(3.80)$ & 18 & 106 \\
\hline SF & $57.56(28.80)$ & 100 & 134 \\
\hline RE & $38.06(43.48)$ & 100 & 134 \\
\hline MH & $55.01(10.88)$ & 68 & 134 \\
\hline
\end{tabular}

Note. SD = standard deviation. physical functioning (PF), physical role functioning (RP) role, bodily pain (BP), general health perceptions $(G H)$, vitality $(\mathrm{VT})$, social role functioning (SF), emotional role functioning role $(\mathrm{RE})$, and mental health $(\mathrm{MH})$.

The convergent validity was evaluated associating the HMSE-10 score with other health-related measures and the results are presented in Table 4. There was a lack of correlation between SE beliefs and sociodemographic variables (age, education, laboral status, income, and marital status). HMSE-10 demonstrated a positive correlation with 6 of 8 domains of overall health status (physical functioning, physical role functioning, general health perceptions, vitality, social role functioning, emotional role, functioning role) and negative correlation with psychopathological symptoms, depression, anxiety, pain catastrophizing, headache-related disability, headache frequency and headache intensity.

A comparison between variables means in the episodic and chronic patients' groups is shown at Table 5. Significant differences were observed in almost all variables between control and clinical groups. The lack of difference was showed only in physical functioning and vitality. The difference between the means of the episodic and chronic headache patients had a magnitude of moderate effect in all the study measures according to statistical power analysis guidelines. ${ }^{19}$ The difference in HIT-6 was the largest one found $(d=0.68)$, showing that in the Brazilian sample chronic migraine patients suffer from a greater 
Table 4. Correlations between HMSE-10 and other measures

\begin{tabular}{|c|c|c|c|c|c|c|c|c|c|c|c|c|c|c|c|c|c|c|}
\hline Variáble & 1 & 2 & 3 & 4 & 5 & 6 & 7 & 8 & 9 & 10 & 11 & 12 & 13 & 14 & 15 & 16 & 17 & 18 \\
\hline 1- HMSE-10 & - & & & & & & & & & & & & & & & & & \\
\hline 2.SRQ & $-21^{*}$ & . & & & & & & & & & & & & & & & & \\
\hline 3. PHQ-9 & $-29 * *$ &, $78 * *$ & . & & & & & & & & & & & & & & & \\
\hline 4-GAD-7 &,$- 21^{*}$ &, $60 * *$ &, $69 * *$ & . & & & & & & & & & & & & & & \\
\hline 5. PCS & $-36 * *$ &, $41^{* *}$ &, $41^{* *}$ &, $49 * *$ & . & & & & & & & & & & & & & \\
\hline 6-HIT-6 &, $34 * *$ &, $52 * *$ &, $55 * *$ & $43^{* *}$ & $45^{* *}$ & - & & & & & & & & & & & & \\
\hline 7. $\mathrm{PF}$ & $24^{* *}$ & $; 53 * *$ & $; 43 * *$ & $-25^{* *}$ & .12 & $-32^{* *}$ & & & & & & & & & & & & \\
\hline 8-RP & $24 * *$ & $-53^{* *}$ & $-45 * *$ & $-30 * *$ & $-25^{* *}$ & $; 41^{* *}$ &, $56 * *$ & . & & & & & & & & & & \\
\hline 9-BP &, 14 & $-54^{* *}$ & $-51^{* *}$ & $; 48^{* *}$ & $-32^{* *}$ & $-50^{* *}$ &, $57^{* *}$ &, $60^{* *}$ & . & & & & & & & & & \\
\hline 10. GH &, $33 * *$ & $-46 * *$ & $.42 * *$ & $; 46 * *$ & $-37 * *$ & $-38^{* *}$ &, $38^{* *}$ & $35 * *$ &, $35 * *$ & . & & & & & & & & \\
\hline 11-VT &, $23 *$ & $-67 * *$ & $.59 * *$ & $-50 * *$ & $-37^{* *}$ & $; 43^{* *}$ &, $37 * *$ & $49 * *$ &, $55^{* *}$ & $36 * *$ & - & & & & & & & \\
\hline 12. SF &, $29 * *$ & $-59 * *$ & $-65 * *$ & $-54 * *$ & $-37 * *$ & $;, 49 * *$ &, $41^{* *}$ & $47^{* *}$ & $49 * *$ &, $36 * *$ &, $53^{* *}$ & - & & & & & & \\
\hline 13- RE & $21^{*}$ & $-56 * *$ & $; 44 * *$ & $-33 * *$ & $-23^{* *}$ & $-35 * *$ &, $43^{* *}$ & $65 * *$ &, $51 * *$ & $28 * *$ &, $61^{* *}$ &, $57 * *$ & . & & & & & \\
\hline 14-MH & 11 & $-33^{* *}$ & $; 43^{* *}$ & $; 44^{* *}$ & $-22^{* *}$ &, $20^{*}$ &, $28^{* *}$ & ,19* &, $33 * *$ &, $24 * *$ & ,20* &, $35 * *$ &, $24 * *$ & . & & & & \\
\hline $17 \quad 15 . \mathrm{HF}$ & $-25^{* *}$ &, $29 * *$ &, $24 * *$ & ,20* &, 16 &, $30 * *$ &,$- 23 * *$ & $-19 *$ & $-25^{* *}$ & $-29 * *$ & $\therefore, 18$ & $-23^{* *}$ & $-23^{* *}$ & -08 & - & & & \\
\hline 16-HI &,$- 19 *$ &, $32^{* *}$ &, $30 * *$ &, $26 * *$ &, $26 * *$ &, $49 * *$ & $-18^{*}$ & $; 24 * *$ & $; 24 * *$ & $; 27^{* *}$ & ; 18 & -16 & ;09 & ,04 & $28^{* *}$ & - & & \\
\hline 17-DD &, 05 &, 06 & -05 & 01 & -02 & -02 &., 16 &, 12 &, 06 & 15 & $; 01$ & -02 &, 05 &, 03 &, 07 &, 02 & - & \\
\hline 18-DT & 10 & -,04 & -01 & , 10 & -06 & ,06 & ,00 & , 12 & , 05 & , 14 & ;,01 & ,05 & -05 & , 12 & , 18* &, 09 &, $49 * *$ & \\
\hline
\end{tabular}

${ }^{*} p<0.05 ;{ }^{* *} p<0.01$. HMSE-10 Headache Management Self-Efficacy Scale-10, SRQ Self-Reporting Questionnaire, PHQ-9 Patient Health Questionnaire 9, GAD-7 Generalized Anxiety Disorder, PCS Pain Catastrophization Scale, HIT-6 Headache Impact Test SF-36, PF physical functioning, RP physical role functioning, BP bodily pain, GH general health perceptions, VT vitality, SF social role functioning, RE emotional role functioning role, MH mental health, HF headache frequency, HI headache intensity, DD Duration of disease (in years), DT duration of treatment (in years)

Table 5. Study measures means in chronic, episodic and group comparisons

\begin{tabular}{|c|c|c|c|c|}
\hline \multirow{2}{*}{ Measures } & \multirow{2}{*}{} & \multicolumn{2}{|c|}{ Mean (SD) } & \multirow{2}{*}{ t-value; Cohen's $d$} \\
\cline { 3 - 4 } & & CM & EM & \multirow{2}{*}{$t=-2.67(133) ; p<0.01 ; d=0.56$} \\
\hline HMSE & 135 & $37.97(15.18)$ & $45.73(12.17)$ & $t=1.94(135) ; p<0.05 ; d=0.41$ \\
\hline SRQ & 137 & $11.56(4.37)$ & $9.65(5.03)$ & $t=3.25(135) ; p<0.001 ; d=0.68$ \\
\hline HIT-6 & 137 & $65.79(6.69)$ & $60.84(7.90)$ & $t=2.03(133) ; p<0.05 ; d=0.43$ \\
\hline PCS & 135 & $16.58(11.28)$ & $41.61(12.07)$ & $t=2.50(132) ; p<0.05 ; d=0.52$ \\
\hline PHQ-9 & 134 & $12.25(5.75)$ & $9.49(6.62)$ & $t=2.21(135) ; p<0.001 ; d=0.45$ \\
\hline GAD-7 & 137 & $54.69(28.51)$ & $65.55(6.12)$ & $t=-1.83(132) ; p>0.05$ \\
\hline PF & 134 & $25.78(39.39)$ & $44.36(42.92)$ & $t=-2.18(132) ; p<0.05 ; d=0.45$ \\
\hline RP & 134 & $32.19(17.73)$ & $41.67(23.13)$ & $t=-2.13(132) ; p<0.05 ; d=0.46$ \\
\hline BP & 134 & $6.16(1.91)$ & $7.00(1.55)$ & $t=-2.29(132) ; p<0.05 ; d=0.49$ \\
\hline GH & 106 & $11.52(3.94)$ & $12.61(3.75)$ & $t=-1,22(104) ; p>0.05 ;$ \\
\hline VT & 134 & $46.09(26.46)$ & $61.15(28.68)$ & $t=-2.64(132) ; p<0.01 ; d=0.55$ \\
\hline SF & 134 & $19.79(36.77)$ & $43.79(44)$ & $t=-3.07(132) ; p<0.01 ; d=0.60$ \\
\hline RE & 134 & $55.25(10.28)$ & $54.94(11.11)$ & $t=0.14(132) ; p>0.05 ; d=0.03$ \\
\hline MH & 134 & & \\
\hline
\end{tabular}

${ }^{*} p<0.05$; ${ }^{* *} p<0.01$. CM Chronic migraine; EM Episodic migraine; HMSE Headache Management Self-Efficacy Scale, SRQ Self-Reporting Questionnaire, PHQ-9 Patient Health Questionnaire 9, GAD-7 Generalized Anxiety Disorder, PCS Pain Catastrophization Scale, HIT-6 Headache Impact Test, PF physical functioning, RP physical role functioning, BP bodily pain, GH general health perceptions, VT vitality, SF social role functioning, RE emotional role functioning role, $\mathrm{MH}$ mental health 
impact on their daily lives compared to episodic migraine patients, which is in line with previous studies. ${ }^{20,21}$

Table 6 shows a multiple regression analysis conducted to test the contribution of headache frequency, headache intensity, psychopathological symptoms, depression, anxiety, and SE beliefs to the prediction of headacherelated disability. Along with headache intensity and depression, SE beliefs accounted for $43 \%\left(R_{2}\right.$ adjusted $=$ $0.43 ; F=17.47 ; p<0.01$ ) of variance in headache-related disability.

Table 6. Regression Analysis for Headache-Related Disability ( $N=131$ )

\begin{tabular}{|c|c|c|c|}
\hline Variable & Beta & $\boldsymbol{t}$ & Sig \\
\hline SRQ & 15 & 1.33 & .19 \\
\hline HF & .07 & .93 & .38 \\
\hline HI & .31 & 4.30 & $<.001^{* *}$ \\
\hline PHQ-9 & .26 & 2.21 & $.03^{*}$ \\
\hline GAD-7 & .03 & .37 & .72 \\
\hline HMSE-10 & -.17 & -2.38 & $.02 *$ \\
\hline${ }^{*} p<0.05 ;{ }^{* *} p<0.01$. By the estimation method Enter. Durbin-Watson: 2.04
\end{tabular}

\section{Discussion}

The present study revealed that the Brazilian short version of Headache Management Self-Efficacy Scale (HMSE10) is a valid and reliable measure of SE beliefs for Brazilian headache patients. HMSE-10 was applied in a heterogeneous sample of migraine patients regarding to sociodemographic (education, income) and clinical measures (headache frequency and intensity), which allows for greater flexibility of future scale applications. The instrument showed good internal consistency, with Cronbach's $a=0.84$ and adequate corrected item-total correlation.

The HMSE-10 showed a mild, but significant positive correlation with 6 of 8 domains of overall health status measured by SF-36. In turn, HMSE-10 scores were negatively associated with psychopathological symptoms, depression, anxiety and pain catastrophizing, headacherelated disability, headache frequency and headache intensity. These findings are in line with previous empirical studies $^{22.24}$ and reinforce that along with other psychological issues (e.g., psychiatric comorbidity, pain catastrophizing, coping styles) SE beliefs evaluation is relevant to headache treatment.

The lack of correlation between SE beliefs and sociodemographic variables (age, education, laboral status, income, and marital status) points to the relevance of the other psychological variables which SE beliefs are associated. Lastly, no correlations were observed between SE beliefs and time of disease or time of treatment. These results support the idea that it is indeed necessary interventions focused on these beliefs for them to be modified. Time of living with the disease or time in treatment by themselves do not modify SE. According to the founder of the concept of self-efficacy, psychological interventions serve as a means of creating and strengthening SE beliefs. ${ }^{25}$

Although our clinical sample was not compared to a control group, it showed anxiety (GAD-7), depression (PHQ-9) and psychopathological symptoms (SRQ) mean scores above cutoff points. These results are consistent with the vast literature about the psychiatric comorbidity observed in migraine patients, mainly depression and anxiety. ${ }^{26.27}$ Moreover, along with headache intensity and depression, $\mathrm{SE}$ beliefs accounted for $43 \%\left(\mathrm{R}_{2}\right.$ adjusted $=$ $0.43 ; F=17.47 ; p<0.01)$ of variance in headache-related disability, supporting that SE beliefs play a key role in adaptation to headaches.

Even with satisfactory results for the purpose of the study, some limitations should be mentioned. First, although the sample was composed of individuals of different educational and socioeconomic levels, it is possible to have a regional bias, since patients were recruited only in Southern Brazil. Second, the patients were all from headache units, which increases the sample bias for those who are not in treatment.

Our findings have clinical and research implications. In presenting our findings and their consonance with previous studies, we hope that clinicians will consider including the investigation of SE beliefs into their clinical practice and that researchers may take these cognitions as a useful indicator of a good response to the proposed treatments.

In brief, the Brazilian Short Version of Headache Management Self-Efficacy (HMSE-10) was considered a valid and reliable measure of headache management selfefficacy beliefs. The HMSE-10 correlations with a variety of relevant clinical measures reinforce its utility in both clinical and research settings.

Acknowledgments: We thank Professor Kenneth Holroyd for providing the copy of original version of HMSE and for the valuable contributions in the process of adaptation of the instrument. Furthermore, our sincere gratitude to 
Juliana Scibicio for the refined statistical advice.

Abbreviations: HMSE Headache Management Self-Efficacy Scale, SRQ Self-Reporting Questionnaire, PHQ-9 Patient Health Questionnaire 9, GAD-7 Generalized Anxiety Disorder, PCS Pain Catastrophizing Scale, HIT-6 Headache Impact Test SF-36 Short Form Health Questionnaire 36 (SF36), Physical functioning (PF), Role functioning/ physical $(\mathrm{RP})$, Bodily pain (BP), General health $(\mathrm{GH})$, Vitality (VT), Social functioning (SF), Role functioning/emotional (RE), Mental health $(\mathrm{MH})$, HF Headache frequency, HI Headache intensity, DD Duration of disease (in years), DT duration of treatment (in years)

Disclosures: No conflicts of interest have been reported by the authors.

\section{References}

1. French DJ, Holroyd KA, Pinell C, Malinoski PT, O'Donnell $F$ and Hill KR. Perceived self-efficacy and headacherelated disability. Headache 2000;40(8):647-656 Doi:10.1046/j.1526-4610.2000.040008647.x

2. Carpino E, Segal S, Logan D, Lebel A and Simons LE. The interplay of pain-related self-efficacy and fear on functional outcomes among youth with headache. J Pain 2014;15(5):527-534 Doi:10.1016/j. ipain.2014.01.493

3. Peck KR and Smitherman TA. Mediator Variables in Headache Research: Methodological Critique and Exemplar Using Self-Efficacy as a Mediator of the Relationship Between Headache Severity and Disability. Headache 2015;55(8):1102-1111 Doi:10.1111/ head. 12633

4. Marlowe N. Self-efficacy moderates the impact of stressful events on headache. Headache 1998;38(9):662-667 Doi:10.1046/j.1526-4610.1998.3809662.x

5. Nicholson RA, Houle T, Rhudy JLand Norton PJ. Psychological risk factors in headache. Headache 2007;47(3):413-426 Doi:10.1111/j.1526-4610.2006.00716.x

6. D'Amico D, Grazzi L, Bussone G, Curone M, Di Fiore P, Usai $S, \ldots$ Raggi $A$. Are depressive symptomatology, self-efficacy, and perceived social support related to disability and quality of life in patients with chronic migraine associated to medication overuse? Data from a cross-sectional study. Headache 2015;55(5):636645 Doi: $10.1111 /$ head. 12534

7. .The International Classification of Headache Disorders, 3rdedition (betaversion). Cephalalgia 2013;33(9):629808 Doi: $10.1177 / 0333102413485658$

8. Beaton DE, Bombardier C, Guillemin F and Ferraz MB.
Guidelines for the process of cross-cultural adaptation of self-report measures. Spine (Phila Pa 1976) 2000;25(24):3186-3191 Doi:10.1097/00007632200012150-00014

9. Borsa JC, Damásio BF and Bandeira DR. Adaptación y validación de instrumentos psicológicos entre culturas: Algunas consideraciones. Paidéia 2012;22(53):423432 Doi: $10.1590 / 1982-43272253201314$

10. Mari JJ and Williams P. A validity study of a psychiatric screening questionnaire (SRQ-20) in primary care in the city of Sao Paulo. Br J Psychiatry 1986; 148:23-26 Doi:10.1192/bjp. 148.1.23

11. Gonçalves DM, Stein AT and Kapczinski F. Avaliação de desempenho do Self-Reporting Questionnaire como instrumento de rastreamento psiquiátrico: um estudo comparativo com o Structured Clinical Interview for DSM-IV-TR. Cad Saúde Pública 2008;24(2):380-390

12. Ciconelli RM, Ferraz MB, Santos W, Meinão I and Quaresma MR. Tradução para a língua portuguesa e validação do questionário genérico de avaliação de qualidade de vida SF-36 (Brasil SF-36). Rev Bras Reumatol 1999;39(3): 143-150

13. Martin M, Blaisdell B, Kwong JW and Bjorner JB. The Short-Form Headache Impact Test (HIT-6) was psychometrically equivalent in nine languages. J Clin Epidemiol 2004;57(12):1271-1278 Doi:10.1016/i. jclinepi.2004.05.004

14. Sehn F, Chachamovich E, Vidor LP, Dall-Agnol L, de Souza IC, Torres IL, . . . Caumo W. Cross-cultural adaptation and validation of the Brazilian Portuguese version of the pain catastrophizing scale. Pain Med 2012;13(11):1425-1435 Doi:10.1111/j.15264637.2012.01492.x

15. Lima Osório F, Vilela Mendes A, Crippa JA and Loureiro SR. Study of the discriminative validity of the PHQ-9 and PHQ-2 in a sample of Brazilian women in the context of primary health care. Perspect Psychiatr Care 2009;45(3):216-227 Doi:10.1111/j.17446163.2009.00224.x

16. Seo JG and Park SP. Validation of the Generalized Anxiety Disorder-7 (GAD-7) and GAD-2 in patients with migraine. J Headache Pain 2015;16:97 Doi: 10.1186/s10194-015-0583-8

17. Seo JG and Park SP. Validation of the Patient Health Questionnaire-9 (PHQ-9) and PHQ-2 in patients with migraine. J Headache Pain 2015;16165 Doi:10.1186/s10194-015-0552-2

18. Cano-García FJ, Rodríguez-Franco L and LópezJiménez AM. A shortened version of the HeadacheSpecific Locus of Control Scale in Spanish population. Headache 2010;50(8):1335-1345 Doi:10.1111/ j. 1526-4610.2009.01588.x 
19. Yang $M$, Rendas-Baum $R$, Varon SF and Kosinski $M$. Validation of the Headache Impact Test (HIT-6 ${ }^{\mathrm{TM}}$ ) across episodic and chronic migraine. Cephalalgia 2011;31(3):357-367 Doi: 10.1177/0333102410379890

20. Berra E, Sances G, De Icco R, Avenali M, Berlangieri M, De Paoli I, ... Nappi G. Cost of Chronic and Episodic Migraine. A pilot study from a tertiary headache centre in northern Italy. J Headache Pain 2015;16(532 Doi:10.1186/s10194-015-0532-6

21. Hansen JS, Bendtsen L and Jensen R. Psychometric properties of the Danish versions of headache-specific locus of control scale and headache management selfefficacy scale. J Headache Pain 2009; 10(5):341-347 Doi:10.1007/s10194-009-0143-1

22. Morasco BJ, Turk DC, Donovan DM and Dobscha SK. Risk for prescription opioid misuse among patients with a history of substance use disorder. Drug Alcohol Depend 2013;127(1-3):193-199 Doi:10.1016/i. drugalcdep.2012.06.032
23. Graef JE, Rief W, French DJ, Nilges P and Nestoriuc $Y$. German Language Adaptation of the Headache Management Self-Efficacy Scale (HMSE-G) and Development of a New Short Form (HMSE-G-SF). Headache 2015;55(7):958-972 Doi:10.1111/ head. 12564

24. Bandura A. Self-efficacy: toward a unifying theory of behavioral change. Psychol Rev 1977;84(2):191-215 Doi:10.1037//0033-295x.84.2.191

25. Hamelsky SW and Lipton RB. Psychiatric comorbidity of migraine. Headache 2006;46(9):1327-1333 Doi: 10.1111/j.1526-4610.2006.00576.x

26. Pompili M, Serafini G, Di Cosimo D, Dominici G, Innamorati $M$, Lester $D, \ldots$ Martelletti P. Psychiatric comorbidity and suicide risk in patients with chronic migraine. Neuropsychiatr Dis Treat 2010;6(81-91 Doi: 10.2147/ndt.s8467

27. Green MW. Headaches: psychiatric aspects. Neurol Clin 2011;29(1):65-80, vii Doi:10.1016/i. ncl.2010.10.004 